\title{
Liquordiagnostik bei erregerbedingten neurologischen Erkrankungen
}

\section{Cerebrospinal Fluid Diagnostics for Neuroinfectious Diseases}

A. Spreer ${ }^{1}$, R. $\mathrm{Nau}^{2,3}$

Klinik für Neurologie, Universitätsmedizin Göttingen

2 Institut für Neuropathologie, Universitätsmedizin Göttingen

${ }^{3}$ Abteilung Geriatrie, Evangelisches Krankenhaus Göttingen-Weende

\section{Zusammenfassung}

$\nabla$

Die Analytik des Liquor cerebrospinalis ist von zentraler Bedeutung in der frühen Diagnosestellung erregerbedingter neurologischer Erkrankungen. Neben der Bestimmung grundlegender liquoranalytischer Parameter wie Zellzahl, Proteine und Laktat, ist die gezielte Suche nach Erregern bakterieller, viraler oder pilzbedingter Infektionen des ZNS entscheidend. Dies kann direkt mittels mikrobiologischer Spezialfärbungen, Kulturmethoden, Nukleinsäure- oder Antigennachweis erfolgen oder indirekt serologisch im Blut oder mittels Nachweis einer erregerspezifischen Antikörpersynthese im Liquor. Neben der Vermittlung von Grundlagen der klinischen Liquordiagnostik soll dieser Fortbildungsartikel den Blick für die speziellen Aspekte der Erregerdiagnostik schärfen. Auf diese Weise soll ermöglicht werden, durch konkrete Fragestellungen an das Labor eine zielgerichtete Analytik zu veranlassen und deren Ergebnisse kritisch zu interpretieren, um dem Patienten die bestmögliche Behandlung zukommen lassen zu können.

\section{Abstract}

$\nabla$

Cerebrospinal fluid analysis is of prime importance to establish an early diagnosis of central nervous system infections. Beside the basic diagnostics containing CSF white cell count, lactate concentration and protein analysis, the targeted search for agents of bacterial, viral or fungal CNS infectious diseases is essential. Decisive methods are bacterial and fungal staining techniques, microbiological culture methods, nucleic acid amplification and antigen detection methods or indirect identification of pathogens by serologic testings including the determination of pathogen-specific intrathecal immunoglobulin synthesis. Besides imparting basic principles of cerebrospinal fluid analysis, this article focuses on special aspects of detection of infectious agents. Well-directed questions and a close communication between clinician and laboratory allow optimal diagnostic analysis for successful confirmation of the diagnosis and for optimal treatment of the patient.

\section{Lernziele}

$\nabla$

Der vorliegende Fortbildungsartikel vermittelt Kenntnisse über:

- die Grundlagen der klinischen Liquordiagnostik

- spezielle Aspekte der Erregerdiagnostik bei neuroinfektiologischen Erkrankungen

- das Veranlassen zielgerichteter Laboranalytik und

- die kritische Interpretation der Laborergebnisse.

\section{Einleitung}

Die Einführung der Lumbalpunktion vor über 100 Jahren [1] war ein entscheidender Durch- bruch in der Diagnostik entzündlicher und neoplastischer Erkrankungen des ZNS. Zunächst wurde durch lichtmikroskopische Untersuchung der Erreger- und Wirtszellen, Bakterienkultur und semiquantitative Bestimmung des Gesamtproteins die Diagnosesicherung der eitrigen Meningitis ermöglicht. Die Weiterentwicklung der Zelldifferenzierung, Proteinanalytik und NukleinsäureNachweismethoden in den folgenden 120 Jahren leistete entscheidende Beiträge zur Erkennung und Behandlung von erregerbedingten, autoimmun-entzündlichen, neoplastischen und neurodegenerativen neurologischen Erkrankungen. Entzündliche ZNS-Erkrankungen manifestieren sich mit verschiedenen Symptomen. Eine Kombination aus Kopfschmerz, Fieber und Meningismus
VNR

2760512015147124859

\section{Bibliografie}

DOI http://dx.doi.org/ 10.1055/s-0034-1398932

Fortschr Neurol Psychiatr 2015; 83: 109-122 @ Georg Thieme Verlag KG Stuttgart · New York . ISSN 0720-4299

\section{Korrespondenzadresse} PD Dr. Annette Spreer Klinik für Neurologie, Universitätsmedizin Göttingen Robert-Koch-Straße 40 37075 Göttingen aspreer@med.unigoettingen.de 
Tab. 1 Typische Befundkonstellationen neuroinfektiologischer Krankheitsbilder.

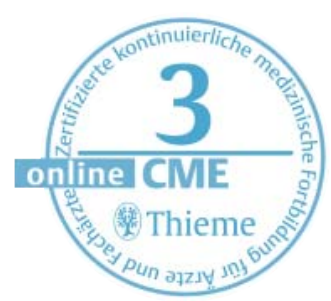

\begin{tabular}{|c|c|c|c|c|}
\hline & bakterielle Meningitis & virale Meningitis & Neuroborreliose & Neurotuberkulose \\
\hline Zellzahl/ul & $\geq 1000$ & $10-500(1000)$ & $30-1000$ & $100-500$ \\
\hline Zytologie & granulozytär & $\begin{array}{l}\text { lymphozytär, } \\
\text { früh gemischt }\end{array}$ & $\begin{array}{l}\text { lympho-monozy- } \\
\text { tär, Plasmazellen }\end{array}$ & „buntes Zellbild“ \\
\hline Eiweiß (mg/l) & $\geq 1000$ & $500-800$ & $500-3000$ & $\geq 1000$ \\
\hline $\mathrm{Q}_{\mathrm{Alb}} \mathrm{CSF} / \mathrm{S} \times 10^{3}$ & $\mathrm{Q}_{\mathrm{Alb}}>25$ & $Q_{\text {Alb }} 8-25$ & $\mathrm{Q}_{\mathrm{Alb}} 8-25$ & $\mathrm{Q}_{\mathrm{Alb}}>25$ \\
\hline Laktat (mmol/l) & $\geq 3,5$ & $<3,5$ & $<3,5$ & $\geq 3,5$ \\
\hline Glc CSF/S & $<0,6$ & & & $<0,6$ \\
\hline $\begin{array}{l}\text { Nachweis und } \\
\text { Hinweis }\end{array}$ & $\begin{array}{l}\text { Gram-Präparat, } \\
\text { Kultur, (PCR) }\end{array}$ & $\begin{array}{l}\text { PCR } \\
\text { Serologie/Al im } \\
\text { Verlauf }\end{array}$ & $\begin{array}{l}\mathrm{Al} \geq 1,5(4-6 \mathrm{Wo}) \\
\lg M>\lg G>\lg A\end{array}$ & $\begin{array}{l}\text { Präparat, Kultur, PCR, } \\
\lg A>\lg M>\lg G\end{array}$ \\
\hline
\end{tabular}

lässt rasch an eine Meningitis denken. Eine zusätzliche qualitative und quantitative Bewusstseinsminderung spricht für eine Meningoenzephalitis. Infektionen des ZNS können sich jedoch ebenso durch epileptische Anfälle oder eine Vielzahl anderer, neu aufgetretener neurologischer oder psychiatrischer Symptome manifestieren. Insbesondere muss dabei an eine Meningoenzephalitis gedacht werden, wenn Fieber oder andere klinische Zeichen auf eine Infektion hinweisen.

Jede neue neurologische oder psychopathologische Symptomatik, die gemeinsam mit Fieber auftritt, muss an eine ZNS-Infektion denken lassen!

In diesem Fall ist die Durchführung einer Liquoranalytik diagnostisch wegweisend und muss angestrebt werden. Analog zur Regel \#10 in Samuel Shems Medizinklassiker „House of God“ [3] „If you don't take a temperature, you can't find a fever“ gilt: „Wer nicht Liquor punktiert, kann keine Meningitis diagnostizieren.“

Oft lassen sich bereits aus der Bestimmung weniger Notfallparameter aus dem Liquor (Leukozytenzahl, Laktat, Gesamtproteingehalt, Gramfärbung zur Detektion von Bakterien) die für die weitere Diagnostik und Therapie entscheidenden Informationen ableiten ( $\bullet$ Tab. 1). Diese Analytik steht im Rahmen der Notfallversorgung auch in nicht-spezialisierten Laboratorien zur Verfügung. Hingegen kann eine Diagnose trotz erweiterter Liquoranalytik in Speziallaboratorien einschließlich Zytologie, Quantifizierung der Blut-Liquor-Schrankenfunktion und der intrathekalen Immunglobulinsynthese, mikrobiologischer Kulturen, Spezialfärbungen und PCR ungeklärt bleiben. Oft bedarf die Diagnose der Zusammenschau des „klinischen Puzzles“, der zusammengetragenen Informationen aus Anamnese, Untersuchungsbefunden und der kompetenten und kritischen Beurteilung laboranalytischer, mikrobiologischer, bildgebender und neurophysiologischer Zusatzdiagnostik.

\section{Lumbalpunktion \\ $\nabla$}

Eine diagnostische Liquorpunktion erfolgt unter aseptischen Bedingungen in sitzender oder seitlich liegender Position des Patienten zwischen den Wirbelkörpern LWK 3/4, LWK 4/5 oder LWK $5 /$ SWK 1. Eine Punktion weiter kranial (bereits ab LWK 2/3) geht mit einem erhöhten Risiko einer Konus-/Kaudaschädigung einher [4]. Wichtig ist eine möglichst maximale Ventralflexion der LWS unter Ausbildung eines „Katzenbuckels“. Die Höhe LWK 4 lässt sich durch eine gedachte Verbindungslinie zwischen den Beckenkämmen des Patienten lokalisieren. Die Punktion erfolgt mit einer „atraumatischen“ Sprotte-Nadel oder mit einer Quincke-Nadel (beide 20-24 Gauge), wobei unter Routinebedingungen insbesondere bei jungen Patienten die Verwendung der Sprotte-Nadeln bevorzugt werden sollte. So reduziert die Verwendung einer 22G-Sprotte-Nadel das Risiko eines postpunktionellen Syndroms im Vergleich zu einer 22G-Quincke-Nadel von 18,9\% auf 6,7\% [5]. Mit dem Lebensalter nimmt das Risiko des postpunktionellen Syndroms ab und ist bei alten Patienten gering [6, 7].

Hygienemaßnahmen. Die Wahrung steriler Bedingungen ist nicht nur zur Vermeidung iatrogener Infektionen unabdingbar, sondern vermeidet auch eine artifizielle Keimbeimengung in die gewonnene Liquorprobe. Dazu gehören eine gründliche Desinfektion der Einstichstelle, die Verwendung eines sterilen Abdeck- oder Lochtuchs und steriler Handschuhe [8]. Der punktierende Arzt soll insbesondere dann einen Mundschutz tragen, wenn durch Sprechen (z.B. Beruhigung des Patienten, Erklärungen für Studenten) eine Tröpfchenbildung möglich ist oder mit für den Arzt infektiösem Punktat zu rechnen ist. Auch bei Durchführung einer Liquordruckmessung wird aufgrund des erhöhten Zeitaufwands das Tragen eines Mundschutzes empfohlen. Die Druckmessung erfordert eine Liquorpunktion in liegender Position, die Normalwerte betragen $10-25 \mathrm{~cm}$ $\mathrm{H}_{2} \mathrm{O}$ [4].

Es ist wichtig, Sonderfälle der Liquorgewinnung aus einer externen Ventrikeldrainage oder mittels subokzipitaler Liquorpunktion dem Labor mitzuteilen, da zur Beurteilung andere Normalwerte herangezogen werden. 
Kontraindikationen. Absolute Kontraindikationen für eine lumbale und subokzipitale Liquorpunktion sind eine intrakranielle Druckerhöhung mit drohender Herniation, z. B. eine in der cerebralen Bildgebung erkennbare Mittellinienverlagerung, oder das Aufbrauchen der suprachiasmalen und perimesencephalen Zisternen oder oberflächliche oder tiefe Entzündungen im Punktionsbereich. Eine Kontraindikation besteht ferner bei erhöhtem Blutungsrisiko. So erfordert eine bestehende Antikoagulation mit neuen oralen Antikoagulanzien (NOAK) die Pausierung entsprechend der jeweiligen Wirkungsdauer, bei Vitamin-K-Antagonisten der Ausgleich der INR-Werte $<1,5$ oder bei therapeutischer Heparinisierung deren Pausierung bis zur Normalisierung der partiellen Thromboplastinzeit (PTT). Die Punktion bei einer Thrombopenie $<50000 / \mu l$ sollte vermieden werden, eine

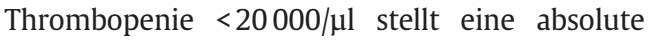
Kontraindikation dar, ggfs. sollte eine Thrombozytensubstitution erfolgen. Bei Therapie mit Thrombozytenaggregationshemmern sollte eine strenge Nutzen-Risiko-Abwägung unter Beachtung des Präparats, der Dosis und der Dringlichkeit der Liquoranalytik erfolgen.

Notwendigkeit der cerebralen Bildgebung. Im klinischen Alltag stellt sich oft die Frage nach der Notwendigkeit einer cerebralen Bildgebung vor einer lumbalen Liquorpunktion. In dieser Frage teilen viele Autoren unsere Auffassung, dass eine gründliche klinisch-neurologische Untersuchung (einschließlich Spiegelung des Augenhintergrunds zum Ausschluss von Stauungspapillen) das Risiko einer kritischen Erhöhung des intracerebralen Drucks ausreichend abschätzt, um eine lumbale Liquorpunktion vornehmen zu können. Vor einer Liquorpunktion muss eine cerebrale Bildgebung erfolgen, wenn eine quantitative oder qualitative Bewusstseinsstörung vorliegt, die die neurologische Beurteilbarkeit des Patienten beeinträchtigt, z.B. bei einer Vigilanzminderung mit einem GCS $<10$. Eine cerebrale Bildgebung vor der Punktion ist indiziert, wenn ein fokal-neurologisches Defizit (nicht bei isolierter Hirnnervenparese) oder eine Stauungspapille nachweisbar ist, wenn epileptische Anfälle neu aufgetreten sind oder wenn eine schwere Immunsuppression vorliegt [2].

Indikation für eine cerebrale Bildgebung vor einer LP [2]:

- Nachweis eines fokalneurologischen Defizits (nicht isolierte Hirnnervenparese)

- neu aufgetretene epileptische Anfälle

- Vorhandensein von Stauungspapillen

- quantitative oder qualitative Bewusstseinsstörung $($ GCS $<10)$

- Vorliegen einer schweren Immunsuppression

In der Regel sollte ein Volumen von $10 \mathrm{ml}$ Liquor entnommen werden $[4,9]$. Aufgrund der physio- logischen Liquorproduktion eines Erwachsenen von 500 bis $600 \mathrm{ml}$ pro Tag bei einem Gesamtvolumen von ca. $150 \mathrm{ml}$ ergibt sich ein Turnover von 3- bis 4-mal täglich und die Entnahme von $10 \mathrm{ml}$ ist in etwa einer halben Stunde ausgeglichen. Das bei einer Liquorpunktion entnommene Volumen hat keinen großen Einfluss auf das Auftreten postpunktioneller Kopfschmerzen [10], hingegen limitiert ein zu geringes Probenvolumen die Möglichkeiten der Analytik. Der frisch entnommene Liquor und ungefähr zeitgleich gewonnenes Se$\operatorname{rum}(<2 \mathrm{~h})$ sollten umgehend in ein entsprechend qualifiziertes Labor weitergeleitet werden. Eine zu lange Transportzeit (>30-60 min) reduziert die Qualität und Sensitivität der Analytik insbesondere für Zytologie und Bakteriologie.

\section{Präanalytik \\ $\nabla$}

In der Diagnostik viraler, bakterieller oder pilzbedingter Infektionen ist die Wahl des geeigneten Nachweisverfahrens von dem vermuteten Erregerspektrum und damit unmittelbar von der Fragestellung des behandelnden Arztes abhängig. In - Tab. 2 ist eine Auswahl neuroinfektiologisch wichtiger Erreger und ihrer üblichen Nachweismethoden aufgelistet. Der direkte mikroskopische und kulturelle Erregernachweis ist für akute ZNSInfektionen durch Bakterien und Pilze entscheidend. Dafür muss der Liquor steril asserviert und schnellstmöglich analysiert werden. Bei zu niedrigen oder zu hohen Temperaturen und langer Transportzeit können Bakterien im nährstoffarmen Liquor unkontrolliert absterben und die Sensitivität des mikrobiologischen Erregernachweises kann abfallen. Besonders empfindlich sind Meningokokken und Haemophilus influenza. Bei Verdacht auf eine bakterielle Meningitis muss der gewonnene Liquor deshalb unzentrifugiert und bei Raumtemperatur schnellstmöglich in ein mikrobiologisches Labor transportiert werden. Dauert der Transport deutlich länger als $30 \mathrm{~min}$, überleben empfindliche Meningitiserreger zuweilen besser, wenn 1-5 ml Liquor (nicht die gesamte Probe) in eine Blutkulturflasche gegeben werden [11]. Bei Verdacht auf eine akute virale Meningoenzephalitis hat die Amplifikation der Erreger-DNA oder -RNA mittels PCR oft entscheidende Bedeutung. Dafür sollte möglichst unzentrifugierter Liquor bei $4{ }^{\circ} \mathrm{C}$ gelagert werden und die Analyse innerhalb von 1 bis 2 Tagen erfolgen. Bei subakuten oder chronischen ZNS-Infektionen basiert die Diagnostik oft auf dem indirekten Erregernachweis mittels serologischer Untersuchungen aus Blut und Liquor.

\section{Stufendiagnostik der Liquoranalytik $\checkmark$}

Jede entnommene Liquorprobe soll zusammen mit möglichst zeitgleich entnommenem Serum $(<2 \mathrm{~h})$ fachgerecht analysiert werden. Dabei wer-

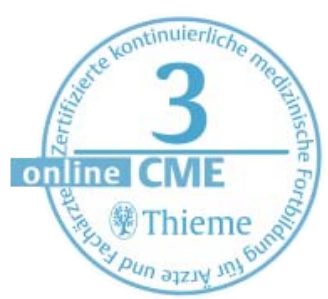


Tab.2 Auswahl neuroinfektiologisch wichtiger Erreger und ihre üblichen Nachweismethoden.

\begin{tabular}{|c|c|c|c|}
\hline Krankheitsbild & Erreger & \multicolumn{2}{|l|}{ Diagnostik } \\
\hline \multirow[t]{4}{*}{$\begin{array}{l}\text { ambulant erworbene bakterielle } \\
\text { Meningitis }\end{array}$} & Streptococcus pneumoniae & \multirow{8}{*}{$\begin{array}{l}\text { Mikroskopie } \\
\text { (Gram-Präparat), } \\
\text { Kultur, Antigen- } \\
\text { Nachweis, PCR } \\
\text { (spezifische, Mul- } \\
\text { tiplex-, 16S-RNA- } \\
\text { PCR) }\end{array}$} & $\begin{array}{l}\text { grampositive, überwiegend extrazelluläre } \\
\text { Diplokokken }\end{array}$ \\
\hline & Neisseria meningitides & & $\begin{array}{l}\text { gramnegative, überwiegend intrazelluläre } \\
\text { Diplokokken }\end{array}$ \\
\hline & Haemophilus influenzae & & $\begin{array}{l}\text { gramnegative, überwiegend extrazelluläre } \\
\text { Stäbchen }\end{array}$ \\
\hline & Listeria monocytogenes & & grampositive Stäbchen \\
\hline \multirow[t]{2}{*}{ Neugeborenen-Meningitis } & Escherichia coli $K 1$ & & gramnegative Stäbchen \\
\hline & B-Streptokokken & & $\begin{array}{l}\text { grampositive, überwiegend extrazelluläre } \\
\text { Kettenkokken }\end{array}$ \\
\hline \multirow[t]{2}{*}{$\begin{array}{l}\text { Hirnabszess, nosokomiale Infek- } \\
\text { tion, Immunsuppression }\end{array}$} & $\begin{array}{l}\text { Staphylococcus aureus und andere Staphy- } \\
\text { lokokken }\end{array}$ & & $\begin{array}{l}\text { grampositive, überwiegend extrazelluläre } \\
\text { Haufenkokken }\end{array}$ \\
\hline & $\begin{array}{l}\text { Enterobacteriaceae oder Pseudomonas } \\
\text { aeruginosa }\end{array}$ & & gramnegative Stäbchen \\
\hline Neuroborreliose & Borrelia burgdorferi s. I. & \multicolumn{2}{|c|}{ Serologie, Borrelien-AI, (PCR nur in Ausnahmefällen), CXCL13 } \\
\hline Neurolues & Treponema pallidum & \multicolumn{2}{|c|}{ Serologie, Treponemen-AI } \\
\hline Neurotuberkulose & Mycobacterium tuberculosis & \multicolumn{2}{|c|}{ Mikroskopie (Ziehl-Neelsen- Färbung), Kultur, spezifische PCR } \\
\hline \multirow[t]{5}{*}{ virale Meningoenzephalitis } & Herpes-simplex-Virus (HSV) 1, 2 & \multicolumn{2}{|c|}{ PCR (akute Infektion), HSV-AI (> 10 - 14 d nach Beginn der Symptome) } \\
\hline & Varicella-zoster-Virus (VZV) & \multicolumn{2}{|c|}{ PCR, VZV-AI } \\
\hline & Epstein-Barr-Virus (EBV) & \multicolumn{2}{|l|}{ PCR, EBV-AI } \\
\hline & Cytomegalovirus (CMV) & \multicolumn{2}{|l|}{ PCR, CMV-AI } \\
\hline & $\begin{array}{l}\text { Enteroviren (Coxsackievirus, Echovirus, } \\
\text { Enterovirus) }\end{array}$ & \multicolumn{2}{|l|}{ Gruppen-PCR } \\
\hline Poliomyelitis & Polio-Virus & \multicolumn{2}{|c|}{ PCR, Zellkultur, Serologie, Poliovirus-Neutralisationstest } \\
\hline $\begin{array}{l}\text { Progressive multifokale Leuken- } \\
\text { zephalopathie (PML) }\end{array}$ & JC-Polyomavirus & \multicolumn{2}{|c|}{ PCR, Hirnbiopsie, Serologie zur Risikoabschätzung } \\
\hline $\begin{array}{l}\text { Frühsommer-Meningoenze- } \\
\text { phalitis (FSME) }\end{array}$ & FSME-Virus, RSSE-Virus & \multicolumn{2}{|l|}{ Serologie, FSME-AI } \\
\hline HIV/AIDS & HI-Virus & \multicolumn{2}{|c|}{ Serologie, PCR, HIV-AI } \\
\hline Mumps-Meningitis & Mumps-Virus & \multicolumn{2}{|c|}{ Serologie, PCR, Mumps-AI } \\
\hline Akute Masernenzephalitis, SSPE & Masern-Virus & \multicolumn{2}{|c|}{ Serologie, Masern-AI, PCR } \\
\hline \multirow[t]{3}{*}{ Invasive Pilzinfektionen } & Aspergillus fumigatus & \multirow{2}{*}{\multicolumn{2}{|c|}{ Kultur, Antigen-Nachweis, 18S-RNA-PCR, Hirnbiopsie }} \\
\hline & Candida albicans & & \\
\hline & Cryptococcus neoformans & \multicolumn{2}{|c|}{ Kultur, Mikroskopie (Tusche-Präparat), Antigen-Nachweis } \\
\hline ZNS-Toxoplasmose & Toxoplasma gondii & \multicolumn{2}{|c|}{ PCR, Toxoplasma-AI } \\
\hline
\end{tabular}

den im allgemeinen Notfallanalytik, diagnostisches Grundprogramm und je nach Fragestellung in spezialisierten Laboratorien erfolgende Spezialanalytik unterschieden [12]

\section{Notfallanalytik}

Visuelle Beurteilung. Bereits während und nach der Liquorgewinnung erfolgt durch den punktierenden Arzt die Erstbeurteilung des Liquors mittels visueller Inspektion. Die normalerweise wasserklare Flüssigkeit wird bei einer Zellbeimengung ab ca. 1000 Erythrozyten/ $\mu l$ rötlich, ab einer Leukozyten-

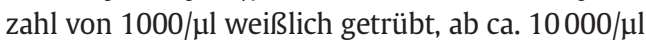
eitrig. Eine zu einer spontanen Bildung von Fibringerinnseln („Spinngewebsgerinnsel“ z. B. bei Neurotuberkulose) führende massive Proteinerhöhung ist selten.

Entzündungsparameter. Das Notfallprogramm der Liquoranalytik umfasst die manuelle Zellzählung in der Fuchs-Rosenthal-Zählkammer (normale Leukozytenzahl im Liquor $\leq 4 / \mu l$, keine Erythrozyten), die Bestimmung von Gesamteiweiß (Obergrenze ca. 400 - $500 \mathrm{mg} / \mathrm{l}$, besser ist die Bestimmung des Liquor/Serum-Albumin-Quotienten $\left[Q_{A l b}\right]$ ) sowie des Laktatwerts im Liquor (Le- bensalter-abhängige Normwerte für 0 - 15 Jahre: 1,5 - 1,8 mmol/l; 16 - 50 Jahre: 1,5 - 2,1 mmol/l; $>50$ Jahre: $1,7-2,6 \mathrm{mmol} / \mathrm{l})$. Wird anstelle von Laktat Glukose im Liquor bestimmt, sind die parallele Beurteilung der Serumglukose und die Bestimmung des Liquor/Serum-Quotienten notwendig. Dieser beträgt bei Gesunden ca. 0,6 (Liquorglukose $45-80 \mathrm{mg} / \mathrm{dl}$ bei normaler Serumglukose) und ist bei bakterieller Meningitis häufig erniedrigt (Liquor/Serum-Glukose-Quotient <0,5) [12, 13]. Zellzahl, Gesamteiweiß und Laktat sind Parameter einer akuten Entzündungsreaktion im ZNS. Diese Parameter sind nicht spezifisch, ihre Konstellation hingegen hilft bei der ersten Einschätzung der Erkrankung, z. B. ob es sich eher um eine akute bakterielle Meningitis oder eine virale Meningitis handelt. Im Verlauf fallen Laktat und Zellzahl bei Behandlungserfolg rasch ab. Jedoch sind diese Parameter unspezifisch, eine Laktaterhöhung als Ausdruck eines durch schädigende Prozesse gesteigerten parenchymatösen Stoffwechsels findet sich bspw. bei entzündlichen (akute bakterielle Meningitis, Neurotuberkulose), vaskulären (akuter ischämischer Schlaganfall), iktalen (prolongierter 
epileptischer Anfall oder Status epilepticus) oder neoplastischen Erkrankungen (Meningeosis neoplastica).

\section{Grundprogramm}

Angesichts der Komplikationsrisiken einer diagnostischen Liquorpunktion (relativ häufiges Vorkommen des den Patienten belastenden postpunktionellen Syndroms, sehr selten potenziell lebensbedrohliche Risiken der Einklemmung, Blutung oder Infektion) ist es aus ethischen Überlegungen $\mathrm{zu}$ fordern, dass jede gewonnene Liquorprobe einem analytischen Grundprogramm entsprechend analysiert wird. Dieses diagnostische Grundprogramm umfasst neben den Parametern der Notfalldiagnostik die Anfertigung und Beurteilung eines zytologischen Präparats, die Bestimmung der Proteine Albumin, Immunglobulin G, A und $M$ in Liquor und Serum und die Auswertung der Quotienten entsprechend den Reiber-Quotientendiagrammen [9].

\section{Gesunder Liquor ist wasserklar! \\ Normalwert der Liquoranalytik:

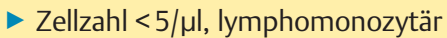 \\ - Gesamteiweiß $<500 \mathrm{mg} / \mathrm{l}$ \\ - $\mathrm{Q}_{\mathrm{Alb}}<(4+$ Alter $/ 15) \times 10^{-3}$ \\ Laktat $<2,1 \mathrm{mmol} / \mathrm{l}$, Glucose $\geq 60 \%$ des Serumwertes \\ Keine intrathekale Ig-Synthese}

\section{Zellzählung und Zytologie}

Im normalen Liquor finden sich weniger als 5 Leukozyten/ $\mu$, bei diesen handelt es sich um Lymphozyten und Monozyten im Verhältnis 2:1 bis 3:1. Finden sich Erythrozyten, sind diese durch artifizielle Blutbeimengung in den Liquor gelangt oder Ausdruck einer subarachnoidalen oder intracerebralen Blutung (Drei-Gläser-Probe zur Differentialdiagnose). Für eine zuverlässige Bestimmung insbesondere geringer Zellzahlen erfolgt die manuelle Auszählung in einer FuchsRosenthal-Zählkammer. Eine automatisierte Zellzählung soll aufgrund unzuverlässiger Befunde insbesondere bei normaler oder niedrig pathologischer Zellzahl vermieden werden. Die Höhe einer Liquorpleozytose und der Nachweis unphysiologischer Zellen wie Granulozyten, aktivierter Lymphozyten, Plasmazellen, Makrophagen oder gar neoplastischer Zellen geben bereits wichtige Hinweise auf die Ätiologie einer entzündlichen Reaktion. Typische Befundkonstellationen sind in - Tab. 1,0 Abb. 1 dargestellt.

\section{Blut-Liquor-Schrankenfunktion und intra- thekale Immunglobulinsynthese}

Für die Beurteilung der Blut-Liquor-Schrankenfunktion und den Nachweis einer lokalen Immunglobulinsynthese ist eine vergleichende Analyse von Liquor und zeitnah, d.h. innerhalb von etwa
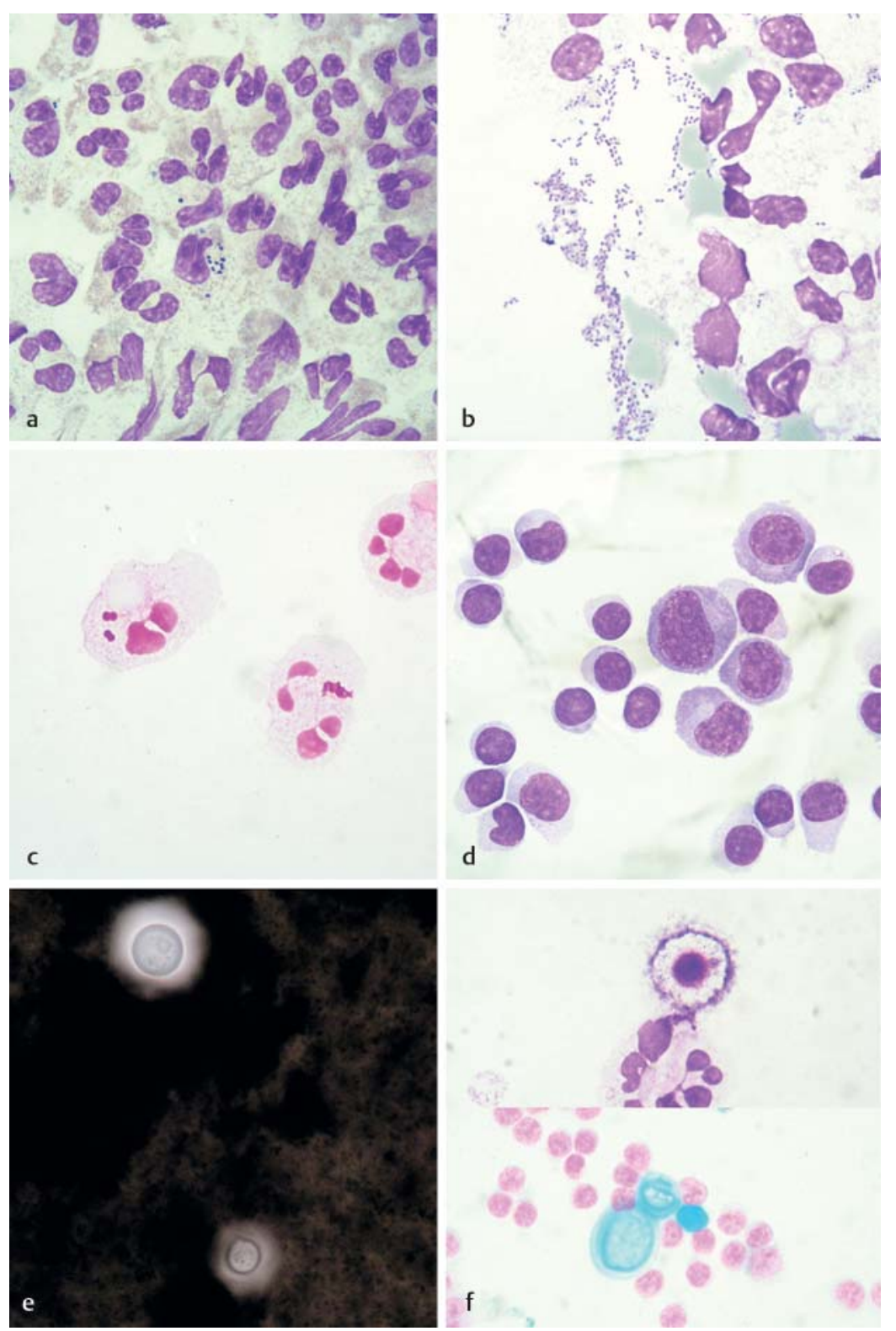

2 Stunden nach Liquorgewinnung, entnommenem Serum notwendig. Liquor wird überwiegend als Filtrat des Bluts von den Plexus chorioidei sezerniert und in seiner Zusammensetzung zusätzlich durch die Extrazellulärflüssigkeit des Hirnparenchyms beeinflusst. Wesentliche Orte der Resorption sind in die Dura eingebettete Ausstülpungen der Arachnoidea in venöse Blutleiter (PacchioniGranulationen) und Prolongationen des Subarachnoidalraums um Hirnnerven und Spinalnervenwurzeln [12, 14]. Ein überwiegender Anteil der Liquorproteine stammt aus dem Serum. Zwischen

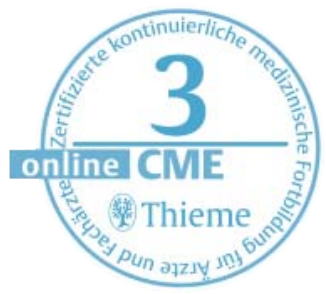




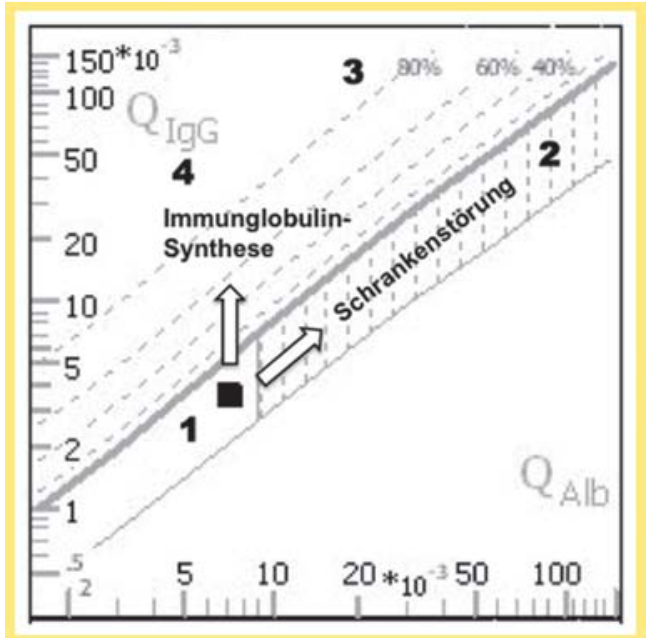

Abb.2 Quotientendiagramm nach Reiber [15]. Der Liquor/Serum-Quotient für Immunglobulin $G\left(Q_{\text {lgG }}\right)$ wird auf den Liquor/Serum-Quotienten des aus dem Serum stammenden Proteins Albumin $\left(Q_{A \mid b}\right)$ bezogen; entsprechende Diagramme existieren auch für IgA und IgM. Es lassen sich folgende Bereiche beschreiben: Bereich 1 entspricht der Lage des Punktes $\left(\mathrm{Q}_{\mathrm{lgG}}\right.$ bezogen auf $\left.\mathrm{Q}_{\mathrm{Alb}}\right)$ im Normalkollektiv. Im Bereich 2 liegt der Punkt bei Vorliegen einer BlutLiquor-Schrankenfunktionsstörung, wenn sowohl Albumin als auch IgG vermehrt aus dem Serum in den Liquor diffundieren. Der Bereich 3 beschreibt eine lokale Immunglobulinsynthese bei gleichzeitig vorliegender Schrankenfunktionsstörung. In den Bereich 4 wandert der Punkt, wenn es bei normaler Diffusion von Serumproteinen in den Liquor (normaler $\mathrm{Q}_{\mathrm{Alb}}$ ) zu einer intrathekalen Immunglobulinsynthese kommt.

den Konzentrationen in Serum und Liquor besteht ein Fließgleichgewicht, das vorwiegend von der Permeabilität der Blut-Liquor- und Blut-Hirnschranke und der Liquorflussgeschwindigkeit abhängt. Die Permeabilität hängt von der Lipophilie und der Molekülgröße der einzelnen Substanzen ab. Ein aus dem Blut stammendes Protein wie z. B. Albumin ist im Ventrikelliquor noch in geringerer Konzentration vorhanden und diffundiert während des Flusses zu den Resorptionsorten in den Liquor hinein, der lumbal höhere Konzentrationen aufweist. So dient das nur extrazerebral in der Leber synthetisierte Albumin als Referenzprotein für die Blut-Liquor-Schrankenfunktion, die durch den Quotienten Albumin im Liquor zu Albumin im Serum $\left(Q_{A l b}\right)$ beschrieben wird (altersabhängiger Normalwert $Q_{A l b}<(4+$ Alter $\left./ 15) \times 10^{-3}\right)$. Ebenfalls gelangen Immunglobuline durch Diffusion aus dem Serum in den Liquor, können jedoch auch im Rahmen einer entzündlichen Erkrankung intrathekal gebildet werden. Eine zusätzliche lokale humorale Immunreaktion wird durch die Darstellung des Immunglobulin-Quotienten Liquor/ Serum $\left(\mathrm{Q}_{\mathrm{gg}}\right)$ der jeweiligen Klasse in Relation zu $\mathrm{Q}_{\text {Alb }}$ deutlich (๑ Abb. 2) [15].

\section{Oligoklonale Banden}

Der Nachweis von nur im Liquor gebildetem oligoklonalem Immunglobulin G mittels isoelektri-
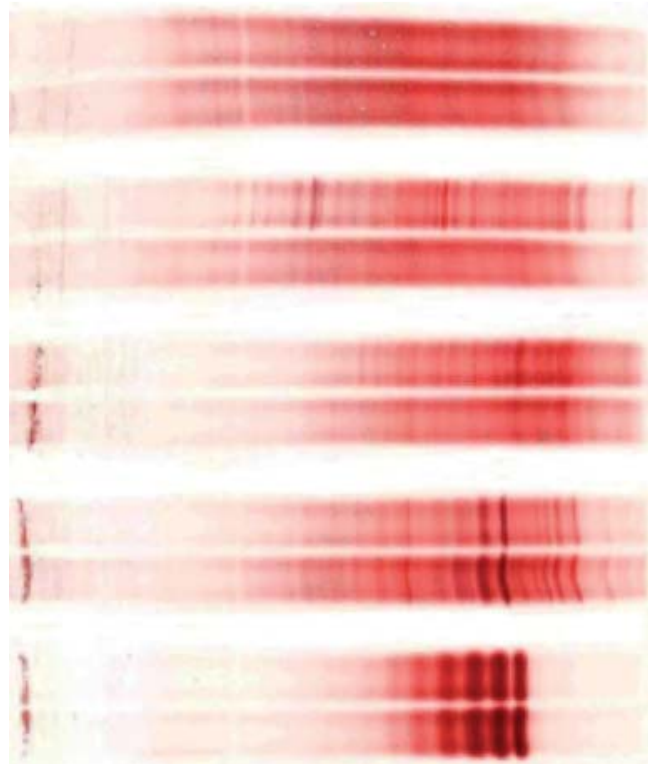

Abb. 3 Befundkonstellationen von IgG-Banden nach Isoelektrischer Fokussierung (hier Detektion durch Immunoblotting). Entsprechend den europäischen KonsensusEmpfehlungen werden 5 Muster unterschieden [16]: Typ 1 Normalbefund ohne Nachweis von Banden in Liquor und Serum; Typ 2 Nachweis von oligoklonalen IgG-Banden (OKB) nur im Liquor (Nachweis einer intrathekalen IgG-Synthese); Typ 3 Nachweis identischer OKB in Liquor und Serum mit zusätzlich isoliert im Liquor nachweisbarer OKB (letztere als Ausdruck einer intrathekalen IgG-Synthese); Typ 4 Nachweis von identischen OKB in Liquor und Serum (Diffusion der IgC aus dem Serum in den Liquor, kein Nachweis einer lokalen IgG-Synthese); Typ 5 Nachweis monoklonaler Banden identisch in Liquor und Serum (Hinweis auf eine systemische Gammopathie, kein Nachweis einer lokalen IgG-Synthese).

scher Fokussierung (IEF) gefolgt von Immundetektion oder Proteinfärbung ist sensitiver als der Nachweis der intrathekalen IgG-Synthese im Quotientendiagramm. Die IEF weist schon eine lokale IgG-Synthese anteilig am Gesamt-IgG im Liquor von wenigen Prozent nach. Entscheidend ist auch dabei der Vergleich zwischen Liquor und Serum. Die Interpretation erfolgt entsprechend den europäischen Konsensusempfehlungen unter Benennung von 5 Mustern [16]. Als Nachweis einer intrathekalen IgG-Synthese wird je nach Methode das Vorhandensein von mindestens 2-3 nicht im Serum nachweisbaren Banden im Liquor interpretiert (Muster 2 und 3, $\odot$ Abb. 3). Die Sensitivität des OKB-Nachweises ist groß, bei geringer krankheitsbezogener Spezifität, da eine Vielzahl von erregerbedingten und autoimmunen entzündlichen ZNS-Erkrankungen zu einer lokalen IgG-Synthese führen kann. Und auch bei nicht klinisch erkrankten Personen finden sich oligoklonale Banden im Liquor in bis zu 5\% der Fälle [17]. Eine sinnvolle Interpretation erfordert somit auch in diesem Punkt eine konkrete klinische Fragestellung. 
Mikroskopischer Erregernachweis

Der direkte Erregernachweis ( $\bullet$ Abb. 1) gelingt bei der akuten bakteriellen Meningitis mittels Gram-gefärbtem Liquorpräparat in 60-90\% der Fälle. Die Sensitivität variiert speziesabhängig (bis $90 \%$ bei Pneumokokken, $<50 \%$ bei L. monocytogenes [18]) und abhängig von der Erregerdichte [19]. Ist der Patient bereits antibiotisch vorbehandelt, kann die Sensitivität des Grampräparats abfallen [20]. In aktuelleren Studien war die Sensitivität des Grampräparats trotz antibiotischer Vorbehandlung unverändert [21, 22]. Wird eine tuberkulöse Meningitis vermutet, sollen Ziehl-Neelsen-gefärbte Liquorpräparate angefertigt werden. Aufgrund der geringen Erregerdichte ist die Sensitivität der Mikroskopie bei Neurotuberkulose begrenzt (5-30\%), sie kann allerdings durch wiederholte Liquoranalysen gesteigert werden [23]. Cryptococcus neoformans kann mikroskopisch mittels Tuschefärbung in ca. 50\% nachgewiesen werden ( 0 Abb. 1e), in diesem Fall ist neben der Kultur auch der Antigennachweis in Liquor und Serum wichtig $[24,25]$.

\section{Antigen-Schnelltest}

Der direkte Erregernachweis mittels Latex-Agglutinationstest kann ergänzende Informationen in der Diagnosestellung akuter bakterieller und pilzbedingter ZNS-Infektionen liefern, mit dem Vorteil rascher Verfügbarkeit. Antigen-Schnelltests gegen bakterielle Meningitiserreger erfassen Streptococcus pneumoniae, Neisseria meningitidis (Serotypen A, B, C, Y, W135), Gruppe-B-Streptokokken und Escherichia coli K1. Jedoch ist die Sensitivität der Antigen-Schnelltests auch nur bei großer Bakteriendichte im Liquor hoch und der Sensitivität eines Grampräparats bei Patienten ohne antibiotische Vorbehandlung nicht überlegen. Diese Tests können die Verdachtsdiagnose einer bakteriellen Meningitis unterstützen, wenn aufgrund antibiotischer Vorbehandlung die Sensitivität der Bakterienkultur reduziert ist. Grundsätzlich darf diese Methode nur als Bestätigung und nicht als Ausschlussdiagnostik interpretiert werden, und die zusätzliche Durchführung weiterer mikrobiologischer Diagnostik inklusive Kultur ist unabdingbar [20]. Hingegen wird die Anwendung von Schnelltests in der Diagnostik einer Kryptokokkeninfektion empfohlen, auch in diesem Fall ergänzend zur zytologischen Beurteilung und Pilzkultur [26, 27]. Diese Tests weisen Polysaccharid-Antigene der bekapselten Hefe Cryptococcus neoformans in Serum und CSF nach [28] und dabei liegt die Sensitivität im Liquor im Vergleich zur Pilzkultur bei 95 - 99\%.

\section{Kulturelle Erregeranzucht}

Die kulturelle Erregeranzucht aus dem Liquor ist der Goldstandard in der Diagnose von bakteriellen und pilzbedingten ZNS-Infektionen und erlaubt neben der Diagnose auch die Empfindlichkeitstes- tung gegenüber antimikrobiellen Pharmaka. Die Sensitivität der Liquorkultur bei Patienten mit akuter bakterieller Meningitis liegt vor Beginn einer antibiotischen Therapie bei $70-85 \%$, sinkt jedoch nach Beginn einer Antibiotikatherapie rasch ab $[20,22]$. Es kommen feste und flüssige Nährmedien zum Einsatz wie z. B. Blutagar und Kochblutagar bei bakterieller Meningitis, Selektivnährböden wie Sabouraud-Agar für Pilze oder LöwensteinJensen-Agar für Mykobakterien, stets in Kombination mit Flüssignährmedien. Bei Verdacht auf eine akute bakterielle Meningitis werden die Kulturen über mindestens $72 \mathrm{~h}$ bei $35-37^{\circ} \mathrm{C}$ unter Raumluft mit $5 \% \mathrm{CO}_{2}$ bebrütet. Andere Verdachtsdiagnosen wie pilzbedingte oder tuberkulöse Meningitiden bedürfen anderer Kulturbedingungen (Nährmedien, Temperatur, Kulturdauer). Es bedarf also der gezielten Fragestellung an das Labor.

\section{Nukleinsäure-Amplifikationsverfahren}

Virale Erreger. Polymerase-Kettenreaktion(PCR)basierte Methoden erlauben mit hoher Sensitivität und Spezifität in nur kurzer Zeit und aus geringen Probenvolumina den Nachweis von nukleinsäurehaltigen Erregern. Für die PCR-Analyse werden Nukleinsäuren in der Regel aus $200 \mu \mathrm{l}$ frischem Gesamtliquor isoliert. Bei Verdacht auf eine tuberkulöse Meningitis wird der Einsatz deutlich größerer Volumina ( $1-5 \mathrm{ml})$ empfohlen. Meistens spielen endogene Polymerase-Inhibitoren bei Liquorproben nur eine untergeordnete Rollen, allerdings sollte insbesondere bei sehr blutigen Liquorproben eine Verminderung der Sensitivität der PCR durch Hämprodukte beachtet werden [29]. Neuroinfektiologisch wichtige Beispiele für die Bedeutung der PCR sind die Herpes-simplex-Enzephalitis (HSE) durch HSV-1/-2, aber auch ZNS-Infektionen durch Varizella-Zoster-Viren (VZV), Epstein-Barr-Viren (EBV), Zytomegalie-Viren (CMV), Enteroviren oder Polyomaviren (z. B. JC-Virus bei progressiver multifokaler Leukenzephalopathie [PML]).

Bakterielle Erreger. In der Diagnostik bakterieller ZNS-Infektionen weisen Real-time-Multiplex-PCRMethoden H. influenzae, N. meningitidis, S. pneumoniae und $L$. monocytogenes mit hoher Sensitivität (87-100\%) und Spezifität (98-100\%) nach [30]. Dies ist insbesondere nach längerer Transportdauer oder bei Proben, die nach Antibiotikagabe gewonnen wurden, bedeutsam. Bei ungewöhnlichen Meningitiserregern kann zudem eine Bakterien-Gruppen-PCR (Nachweis der für die bakterielle 16S-RNA kodierenden DNA) mit anschließender Sequenzierung hilfreich sein $[31,32]$. Als ergänzendes Verfahren hat die PCR Bedeutung in der Diagnostik der Neurotuberkulose, insbesondere, da sie im Vergleich zu der sehr langen Kulturdauer sehr schnell Ergebnisse liefert. Allerdings schwanken die Angaben zu Sensitivität (46-66\%, Angaben zwischen 2 und $100 \%$ ) und Spezifität (97-99\%, Angaben zwischen 75 und $100 \%$ ) sehr, sodass die Interpretation der Ergebnisse besonnen erfolgen muss [33].

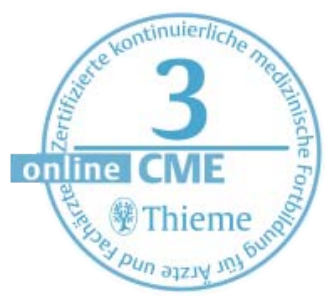


Abb. 4 Formel zur Berechnung des spezifischen Antikörper-In$\operatorname{dex}\left(\right.$ für $\mathrm{Q}_{\mathrm{Ig}}<\mathrm{Q}_{\text {Lim }}$ ).

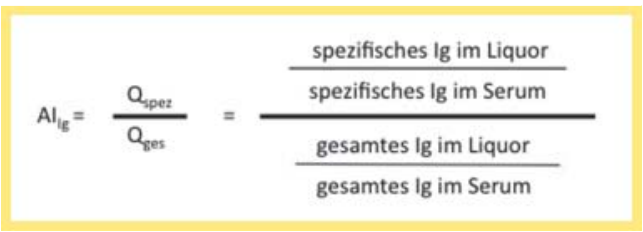

Serologie zum indirekten Erregernachweis Der indirekte Erregernachweis durch die Bestimmung von gegen die Infektionserreger gerichteten Antikörpern spielt insbesondere in der Diagnostik subakuter oder chronischer ZNS-Infektionen eine wesentliche Rolle. Neben der Quantifizierung der Erreger-spezifischen Antikörper im Serum ist dazu die Bestimmung der im ZNS erfolgten humoralen Immunantwort mittels Erreger-spezifischem Antikörper-Index von großer Bedeutung.

\section{Erreger-spezifische intrathekale Immunglobulinsynthese}

Durch Quotientenbildung zwischen Liquor und Serum und Kalkulation des spezifischen Antikörper-Index kann eine intrathekale Erreger-spezifische Antikörpersynthese nachgewiesen werden [34]. Spezies-spezifische Antikörper diffundieren in dem gleichen Verhältnis aus dem Serum in den Liquor wie das Gesamt-Immunglobulin der untersuchten Immunglobulinklasse. Somit sind im Normalfall der spezifische Antikörper-Quotient zwischen Liquor und Serum $\left(\mathrm{Q}_{\text {spez }}\right)$ und der Gesamt-Immunglobulin-Quotient der jeweils untersuchten Immunglobulinklasse zwischen Liquor und Serum $\left(\mathrm{Q}_{\text {ges }}\right)$ gleich. Der als spezifischer Antikörperindex AI bezeichnete Quotient $\mathrm{Q}_{\text {spez }}$ dividiert durch $Q_{\text {ges }}$ ergibt in diesem Fall 1 ( $A$ Abb.4). Findet sich in den Reiber-Quotientendiagrammen eine nachweisbare lokale Immunglobulinsynthese $\left(Q_{\mathrm{Ig}}>\mathrm{Q}_{\mathrm{Lim}}\right.$, z.B. aufgrund einer polyspezifischen Immunreaktion bei Multipler Sklerose), wird $\mathrm{Q}_{\text {spez }}$ auf den oberen Grenzwert des Referenzbereichs bezogen $\left(\mathrm{Q}_{\text {spez }} / \mathrm{Q}_{\mathrm{Lim}}\right)$. Kommt es intrathekal zu einer Synthese von gegen einen Erreger gerichteten Antikörpern, wird $\mathrm{Q}_{\text {spez }}$ größer als $\mathrm{Q}_{\text {ges }}$ (bzw. $\mathrm{Q}_{\text {Lim }}$ ) und der AI-Wert steigt an. Ein AI-Wert $\geq 1,5$ gilt als pathologisch, in diesen Fällen ist eine lokale Antikörpersynthese im ZNS anzunehmen [34] ( $\bullet$ Tab. 2).

\section{Vom klinischen Verdacht zur Diagnosesicherung}

Aus Anamnese, klinischer Untersuchung und Liquor-Notfalldiagnostik ergeben sich oft konkrete Verdachtsdiagnosen, die das weitere diagnostische Vorgehen lenken. Im Folgenden sollen für eine begrenzte Auswahl neuroinfektiologischer Krankheitsbilder spezielle liquoranalytische Aspekte aufgeführt werden, weiterführend wird auf Leitlinien, Übersichtsartikel und Buchbeiträge verwiesen [12, 35 - 37].
Akute bakterielle Meningitis

Da es sich bei der ambulant erworbenen akuten bakteriellen Meningitis um eine lebensbedrohliche Erkrankung mit hoher Letalität und Morbidität handelt, ist eine unmittelbare Diagnosestellung von zentraler Bedeutung. Erreger sind vor allem S. pneumoniae, N. meningitidis, L. monocytogenes und in der Neugeborenenperiode zudem Gruppe-B-Streptokokken und E. coli K1. Die Erreger erreichen das ZNS nach systemischer Infektion (Pneumonie, Sepsis, Endokarditis) hämatogen oder im Sinne einer „Durchwanderungsmeningitis" nach lokaler Infektion (Sinusitis, Mastoiditis, Otitis). Bei traumatischen oder nosokomialen Infektionen (offenes Schädel-Hirn-Trauma, neurochirurgische Operation, externe Ventrikeldrainage) ist mit einem erweiterten Erregerspektrum einschließlich Staphylokokken, Streptokokken und gramnegativen Stäbchen zu rechnen [11]. Eine Verzögerung der antibiotischen Behandlung einer ambulant erworbenen bakteriellen Meningitis um mehr als 6 Stunden („Door-to-Needle“Zeit) führt zu einem massiven Anstieg der Sterblichkeit von $6 \%(<4-6 \mathrm{~h})$ auf über $45 \%(>6 \mathrm{~h})$ [38]. Somit ist es entscheidend, früh an die Möglichkeit einer bakteriellen Meningitis zu denken. Das klinische Vollbild mit einer Symptomen-Trias aus Fieber, Meningismus und Bewusstseinsminderung liegt bei nicht einmal der Hälfte der Patienten mit einer akuten bakteriellen Meningitis vor, wohingegen 2 der 4 Symptome Kopfschmerz, Fieber $\geq 38^{\circ} \mathrm{C}$, Meningismus und Bewusstseinsminderung in $95 \%$ und zumindest 1 Symptom in 99\% der Fälle vorliegt [21].

Die Trias Fieber, Meningismus und Bewusstseinsminderung findet sich bei $<50 \%$ der Patienten mit einer akuten bakteriellen Meningitis.

Besondere Aufmerksamkeit ist geboten bei alten, neugeborenen oder immungeschwächten Patienten, bei ihnen muss die Möglichkeit einer ZNS-Infektion im Zweifel durch eine Liquorpunktion überprüft werden. Der typische Liquorbefund bei einer eitrigen Meningitis weist eine granulozytäre Pleozytose $>1000 / \mu l$, ein Gesamteiweiß >1000 mg/l und ein Laktat $\geq 3,5 \mathrm{mmol}$ auf. Nicht auf eine antibiotische Therapie verzichten darf man bei niedrigen Zellzahlen, jedoch hohen Laktat- und Eiweißwerten im Liquor, in diesen Fällen muss man an die Möglichkeit einer „apurulenten Meningitis“ denken.

Bakterienkultur. Nach raschem Transport ins Labor wird der direkte mikroskopische und kulturelle Nachweis angestrebt. Die Sensitivität insbesondere der Bakterienkultur nimmt nach Beginn einer antibiotischen Behandlung deutlich ab. Deshalb soll, in Abwesenheit von Kontraindikationen, möglichst vor, oder so früh wie möglich nach Beginn einer empirischen Antibiotikatherapie, eine 
Liquorpunktion mit Bakterienkultur angestrebt werden. Bei Kindern führte eine effektive antibiotische Behandlung bereits nach 24-36h zu einer Sterilisierung initial positiver Liquorkulturen in $90-100 \%$ [39].

Blutkultur. Zudem darf nicht vergessen werden, vor Beginn einer empirischen Antibiotikatherapie Blutkulturen und bei Verdacht auf eine Meningokokkenmeningitis Abstriche aus Rachen und/oder steril eröffneten Petechien zu entnehmen.

Vor Beginn einer antibiotischen Behandlung sollen Blutkulturen gewonnen werden.

Ergänzende Methoden wie PCR-Diagnostik und Antigenschnelltest sind bei bakterieller Meningitis insbesondere nach längerer Transportdauer oder bei Proben, die nach Antibiotikagabe gewonnen wurden, bedeutsam. Durch sie kann dann noch eine Erregersicherung erreicht werden, allerdings ohne Erhalt des wichtige Zusatzinformationen liefernden Antibiogramms.

\section{Herpes-simplex-Enzephalitis (HSE)}

Die überwiegend durch HSV-1, seltener durch HSV-2 hervorgerufene fokale nekrotisierende HSE ist in Europa die häufigste sporadische Enzephalitis. Trotz Therapie mit Aciclovir sind Letalität und Morbidität hoch. So kann nach einer HSE nur die Hälfte der Patienten ihr Leben wie vor der Erkrankung weiterführen, und 30\% sterben oder überleben mit schwersten neurologischen Defiziten [40]. Einziger beeinflussbarer prognostischer Faktor ist der frühzeitige Beginn der antiviralen Therapie mit Aciclovir [41]. So muss jedes neue neurologische oder psychopathologische Defizit insbesondere dann an eine Herpes-Enzephalitis denken lassen, wenn es zusammen mit Fieber auftritt. Diagnostisch entscheidend ist die Liquoranalytik. Es findet sich das Bild einer viralen Meningitis mit lymphomonozytärer Pleozytose je nach Grad der meningealen Beteiligung von 5 500 Zellen/ $\mu 1$, die Gesamtproteinwerte liegen zwischen 500 und $800 \mathrm{mg} / \mathrm{l}$, die Laktatwerte im Liquor sind überwiegend normal, können je nach Schwere der Enzephalitis auch leicht erhöht sein $(<3,5 \mathrm{mmol} / \mathrm{l})$. Allerdings findet sich auch in bis zu $5 \%$ der HSE-Fälle ein initial normaler Liquorbefund [42]. Häufig lassen sich Entzündung und Ödem in den unteren und mesialen Anteilen des Temporallappens, der Inselrinde, des Thalamus, des Gyrus cinguli und des frontobasalen Kortex bereits früh im Krankheitsverlauf im cranialen MRT (cMRT) darstellen. Ein unauffälliges cMRT schließt hingegen die Diagnose nicht aus [42]. Gesichert wird die HSE in der Akutphase der Erkrankung mittels PCR, die eine sehr hohe Sensitivität $\geq 95 \%$ und eine ebenso hohe Spezifität von 99\% aufweist. Mittels PCR gelingt der Erregernachweis auch noch nach Beginn der antiviralen Therapie für wenigsten 5 - 7 Tage $[43,44]$. In diesem Frühstadium einer HSE kommt serologischen Verfahren wie der Bestimmung von Antikörperindexwerten noch keine Bedeutung zu. Allerdings werden auch in den ersten $72 \mathrm{~h}$ einer HSE falsch negative PCR-Ergebnisse berichtet [45], sodass in diesen Fällen eine erneute Liquoranalytik 4-7 Tage nach Beginn der klinischen Symptomatik empfohlen wird [42]. Deshalb darf bei begründetem Verdacht auf eine HSE bei negativem PCRErgebnis die antivirale Therapie insbesondere dann nicht unterbrochen werden, wenn die Liquorprobe in den ersten 3 Tagen gewonnen wurde oder aufgrund einer Blutbeimengung die Sensitivität der PCR vermindert sein könnte [33, 42].

\section{Neuroborreliose}

Die Borreliose ist die häufigste durch Zecken übertragene Infektionserkrankung in Europa. Als Multisystemerkrankung betrifft sie neben Haut, Gelenken, selten Herz oder Auge, regelmäßig auch das Nervensystem. Die klinische Präsentation reicht von einer Radikulitis spinaler Nerven mit lymphomonozytärer Meningitis (Meningoradikulitis Garin-Bujadoux-Bannwarth) oder isolierten Hirnnervenparesen bis zu der sehr seltenen Enzephalomyelitis. Die Diagnosesicherung erfolgt mittels Serologie und Liquordiagnostik ([46, 47], zur Übersicht auch [48]). Typischerweise finden sich bei der Neuroborreliose eine vorwiegend lymphozytäre, plasmazellreiche Pleozy-

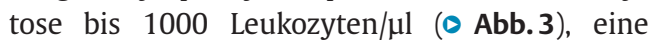
deutliche Schrankenfunktionsstörung mit einem erhöhten Albuminquotienten und erhöhtem Gesamteiweiß, eine lokale Immunglobulinproduktion vom IgM-Dominanztyp und meist normale oder nur leicht erhöhte Werte für Laktat $[12,49]$. Als beweisend für eine Neuroborreliose wird das Vorliegen einer typischen klinischen Befundkonstellation mit einem entzündlichen Liquorbefund und dem Nachweis einer intrathekalen Synthese von gegen Borrelien gerichteten Antikörpern angesehen [46]. Dabei liegt die Sensitivität von pathologisch erhöhten B.-burgdorferi-AI-Werten bei $80 \%$ (<6 Wochen Erkrankungsdauer) bis nahezu $100 \%$ (längere Verläufe). Aufgrund ihrer niedrigen Sensitivität von nur $10-30 \%$ ist die Rolle einer Borrelien-PCR im Liquor auf sehr frühe Krankheitsstadien oder auf Infektionen bei Immunsupprimierten begrenzt [47]. Das im ZNS gebildete B-Zell-anlockende Chemokins CXCL13 wies in einer aktuellen Studie im Liquor eine hohe Sensitivität für eine akute, unbehandelte Neuroborreliose auf und hat das Potenzial, in Zukunft die Diagnostik der Neuroborreliose zu ergänzen [50]. Nicht für die Diagnostik einer Borreliose empfohlen werden gemäß den Leitlinien der Deutschen Gesellschaft für Neurologie (DGN) und der European Federation of Neurological Societies (EFNS) der Antigennachweis aus Körperflüssigkeiten, eine PCR aus Serum oder Urin, Lymphozytentransformationstests, der sog. „Visual Contrast

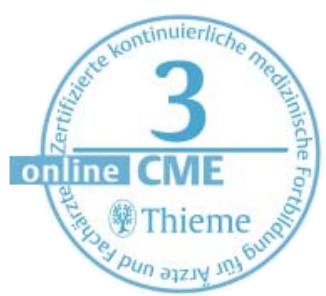


Sensitivity Test“ und der Nachweis einer erniedrigten CD-57-positiven/CD-3-negativen Lymphozytenpopulation $[46,47]$.

\section{FSME}

Bei der typischerweise biphasisch verlaufenden FSME kommt es zunächst nach einer Inkubationszeit von 3 bis 14 Tagen zu einer systemischen Infektion und nach einem erneuten symptomfreien Intervall von 6 bis 10 Tagen bei $10-30 \%$ der Patienten zu einer 2. Krankheitsphase mit ZNS-Beteiligung. Diese impfpräventable, nicht kausal behandelbare Erkrankung manifestiert sich in ca. $50 \%$ als Meningitis, in $40 \%$ als Meningoenzephalitis und in $10 \%$ als Meningoenzephalomyelitis, letztere mit schlechter Prognose [51]. Die Liquoranalytik zeigt in der Phase der ZNS-Infektion das Bild einer viralen Meningoenzephalitis mit 10-1000 Leukozy-

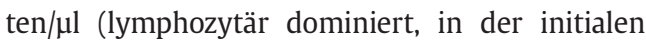
Phase auch granulozytär möglich), eine leichte bis deutliche Schrankenfunktionsstörung und normale Laktatwerte. Zum Zeitpunkt des Auftretens von ZNS-Symptomen hat eine serologische Antwort auf den Erreger stattgefunden, entsprechend wird die Verdachtsdiagnose serologisch im Blut oder durch Nachweis einer intrathekalen Synthese mittels anti-FSME-AI bestätigt [52].

\section{Neurotuberkulose}

Bei dieser in Deutschland seltenen Manifestation der wieder an Bedeutung gewinnenden Tuberkulose ist die Diagnosesicherung oft nicht leicht, und oft ist die Anamnese einer früheren oder aktuellen systemischen Tuberkulose entscheidend. Bei der tuberkulösen Meningitis als häufigster Form der Neurotuberkulose stehen die Symptome einer basalen Meningitis mit Liquorzirkulationsstörung im Vordergrund. Der sehr eiweißreiche Liquor weist manchmal durch spontane Gerinnung „Spinngewebsgerinnsel“ auf, die Gesamteiweißwerte liegen bei $2000-10000 \mathrm{mg} / \mathrm{l}$, $\mathrm{Q}_{\text {Alb }}$ oft bei $>25 \times 10^{-3}$ [12]. Die Liquor-Leukozy-

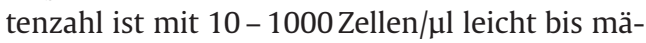
ßig erhöht, das Zellbild je nach Erkrankungsstadium variabel mit überwiegendem Nachweis einer „bunten“ Mischpleozytose aus Granulozyten, Monozyten und Lymphozyten. Wegweisend können eine Dominanz der lokalen IgA-Synthese in den Quotientendiagrammen und ein regelhaft erhöhter Laktatwert im Liquor sein [53]. Die Diagnosesicherung ist oft nicht einfach. Die teils niedrigen Sensitivitäten von Mikroskopie und PCR können durch wiederholte Analytik und große Probenvolumina erhöht werden, kulturelle Methoden bedürfen weiterhin einer langen Inkubationszeit von 6 bis 8 Wochen.

\section{Septische Herdenzephalitis} und Hirnabszess

Fortleitung aus benachbarten Infektionsfoci, hämatogene Streuung oder Infektion nach offenen Traumen oder Operationen sind die häufigsten
Ursachen einer Herdenzephalitis oder eines Abszesses. Das Erregerspektrum wird dabei von der Genese und der Abwehrlage des Patienten bestimmt. Bei Abszessen ist eine Mischinfektion aus aeroben und anaeroben Bakterien typisch und umfasst vor allem Streptokokken, Staphylokokken, Anaerobier und gramnegative aerobe Bakterien. Bei Immunsupprimierten müssen auch Pilze (Aspergillus, Candida, Cryptococcus und Mucorales spec.) und bei entsprechender Reiseanamnese Protozoen und Würmer in Betracht gezogen werden [54]. Die entscheidende diagnostische Maßnahme ist die cerebrale Bildgebung mittels cMRT oder alternativ cCT mit Kontrastmittel. Bei 11 von 12 Patienten, die mit einer septischen Herdenzephalitis lumbalpunktiert wurden, fanden sich entzündliche Liquorveränderungen unterschiedlicher Ausprägung, die den bei viralen Meningoenzephalitiden gefundenen Veränderungen ähneln [55]. Für eine septische Herdenzephalitis pathognomonische Befunde sind nicht bekannt. Die Erregeranzucht aus dem Liquor gelingt nur in Ausnahmefällen. Bei der septisch-metastatischen Variante steht die Entzündungsreaktion im Vordergrund, sodass in diesen Fällen die entzündlichen Liquorveränderungen ausgeprägter sind als bei der septisch-embolischen Variante mit im Vordergrund stehender ischämischer Komponente [55]. Die Liquoranalytik hat in den meisten Fällen für die Diagnostik des Hirnabszesses keinen besonderen Stellenwert. Die Liquorveränderungen sind unspezifisch (leichte bis mäßige Pleozytose, Proteinerhöhung). Der Liquor kann selten auch normal sein. Auch für die Erregeridentifikation ist die Liquordiagnostik in der Regel nicht bedeutsam. Bei raumfordernden Abszessen ist die Liquorentnahme wegen der Gefahr der transtentoriellen und/oder foraminalen Herniation kontraindiziert.

Entscheidend für die Erregeridentifikation sind bei beiden Erkrankungen die Entnahme von Blutkulturen vor Beginn der antibiotischen Therapie sowie beim Hirnabszess die Gewinnung von Abszessinhalt [54].

\section{Zusammenfassung}

\section{$\nabla$}

Eine frühzeitige Diagnosestellung neuroinfektiologischer Erkrankungen wie der bakteriellen Meningitis oder der Herpesenzephalitis ist für die Therapie und Prognose der Patienten von entscheidender Bedeutung. Grundsätzlich im Zentrum stehen die klinische Verdachtsdiagnose als Zusammenschau der Informationen aus Anamnese einschließlich möglicher Immunsuppression und Reiseanamnese, internistischem und neurologischem Untersuchungsbefund und die kompetente und kritische Beurteilung laboranalytischer, mikrobiologischer und radiologischer Zusatzdiagnostik. Entscheidend ist jedoch, niederschwel- 
lig an die Möglichkeit einer ZNS-Infektion zu denken und dann eine Liquoranalytik zu veranlassen. Für eine adäquate Analytik bedarf das Labor der klinischen Angaben und der engen Rücksprache mit den behandelnden Kollegen. Die Notfallanalytik liefert bereits durch Inspektion, Zellzahl-, Gesamteiweiß- und Laktatbestimmung wichtige orientierende Informationen. Zytologie, Auswertung der Quotientendiagramme und der oligoklonalen Banden ergeben oft krankheitstypische Befundmuster. Für die Diagnosesicherung sind eine gezielte Fragestellung und der direkte oder indirekte Erregernachweis mittels bakteriologischer Färbungen, Kulturen, Antigen-Nachweis, PCR, Serologie oder Antikörper-Index erforderlich.

Interessenkonflikt: Die Autoren geben an, dass kein Interessenkonflikt besteht.

Literatur

1 Quincke $H$. Die Lumbalpunction des Hydrocephalus. Berliner klinische Wochenschrift 1891; 891: 929-933

2 Schut ES, de Gans J, van de Beek D. Community-acquired bacterial meningitis in adults. Pract Neurol 2008; 8: $8-23$

3 Shem S. The House of God: Delta Trade Paperbacks; 1978

4 Woitalla D, Otto M, von Stuckrad-Barre S et al. Diagnostische Liquorpunktion. In: Diener H, Weimar C eds Leitlinien für Diagnostik und Therapie in der Neurologie. 5. ed. Stuttgart: Thieme; 2012: 1017 1023

5 Carson $D$, Serpell $M$. Choosing the best needle for diagnostic lumbar puncture. Neurology 1996; 47: $33-37$

6 Djukic M, Schulz D, Schmidt $H$ et al. Cerebrospinal fluid findings in geriatric patients from 2008 to 2011. Z Gerontol Geriatr 2013; 46: 353-357

7 Popp J, Riad M, Freymann K et al. Diagnostic lumbar puncture performed in the outpatient setting of a memory clinic. Frequency and risk factors of postlumbar puncture headache. Nervenarzt 2007; 78: $547-551$

8 Anforderungen an die Hygiene bei Punktionen und Injektionen - Empfehlung der Kommission für Krankenhaushygiene und Infektionsprävention beim Robert Koch-Institut. Bundesgesundheitsblatt 2011; 54: $1135-1144$

9 Petereit H, Sindern E, Wick M. Leitlinien der Liquordiagnostik und Methodenkatalog der Deutschen Gesellschaft für Liquordiagnostik und Klinische Neurochemie. Heidelberg: Springer Medizin; 2007

10 Kuntz KM, Kokmen E, Stevens JC et al. Post-lumbar puncture headaches: experience in 501 consecutive procedures. Neurology 1992; 42: 1884-1887

11 Nau R. Liquordiagnostik bei bakteriellen ZNS-Erkrankungen. In: Zettl UK, Lehmitz R, Mix E eds, Klinische Liquordiagnostik. 2 ed. Berlin: de Gruyter; 2005: $301-314$

12 Wildemann B, Oschmann P, Reiber H. Neurologische Labordiagnostik. Stuttgart: Thieme; 2006

13 Kleine T. Notfall-Programm. In: Zettl UK, Lehmitz R, Mix E eds Klinische Liquordiagnostik. 2. ed. Berlin: de Gruyter; 2005: 127-134

14 Tumani H, Kluge H. Anatomie und Physiologie des Liquorsystems. In: Zettl UK, Lehmitz R, Mix E eds Klinische Liquordiagnostik. 2. ed. Berlin: de Gruyter; 2005: $39-55$
15 Reiber $H$. Flow rate of cerebrospinal fluid (CSF)-a concept common to normal blood-CSF barrier function and to dysfunction in neurological diseases. J Neurol Sci 1994; 122: 189-203

16 Andersson M, Alvarez-Cermeno J, Bernardi $G$ et al Cerebrospinal fluid in the diagnosis of multiple sclerosis: a consensus report. J Neurol Neurosurg Psychiatry 1994; 57: 897-902

17 Wurster U, Stachan R, Windhagen A et al. Reference values for standard cerebrospinal fluid examinations in multiple sclerosis. Results from 99 healthy volunteers. In: ECMID:Multiple Sclerosis. 2006: 228

18 Gray $L D$, Fedorko DP. Laboratory diagnosis of bacterial meningitis. Clin Microbiol Rev 1992; 5: 130-145

19 La Scolea LJJr, Dryja D. Quantitation of bacteria in cerebrospinal fluid and blood of children with meningitis and its diagnostic significance. J Clin Microbiol 1984; 19: 187-190

20 Tunkel AR, Hartman BJ, Kaplan SL et al. Practice guidelines for the management of bacterial meningitis. Clinical infectious diseases: an official publication of the Infectious Diseases Society of America 2004; 39: $1267-1284$

21 van de Beek D, de Gans J, Spanjaard L et al. Clinical features and prognostic factors in adults with bacterial meningitis. N Engl J Med 2004; 351: 1849-1859

22 Nigrovic LE, Malley R, Macias CG et al. Effect of antibiotic pretreatment on cerebrospinal fluid profiles of children with bacterial meningitis. Pediatrics 2008; $122: 726-730$

23 Kennedy DH, Fallon RJ. Tuberculous meningitis. JAMA 1979; 241: 264-268

24 Perfect JR. Cryptococcus neoformans. In: Mandell GL, Bennett JE, Dolin R eds Principles and Practice of Infectious Diseases. Philadelphia, Pennsylvania: Elsevier; 2005: 2997-3011

25 Marchetti O, Lamoth F, Mikulska M et al. ECIL recommendations for the use of biological markers for the diagnosis of invasive fungal diseases in leukemic patients and hematopoietic SCT recipients. Bone Marrow Transplant 2012; 47: 846-854

26 Portegies P, Solod L, Cinque P et al. Guidelines for the diagnosis and management of neurological complications of HIV infection. Eur J Neurol 2004; 11: 297-304

27 Arendt G, Eggers C, Furrer $H$ et al. Diagnostik und Therapie HIV-1-assoziierter neurologischer Erkrankungen. In: Diener H, Weimar C eds Leitlinien für Diagnostik und Therapie in der Neurologie. 5. ed. Stuttgart: Thieme; 2012: 560-569

28 Bennett JE, Hasenclever HF, Tynes BS. Detection of Cryptococcal Polysaccharide in Serum and Spinal Fluid: Value in Diagnosis and Prognosis. Trans Assoc Am Physicians 1964; 77: 145-150

29 Debiasi RL, Tyler KL. Molecular methods for diagnosis of viral encephalitis. Clin Microbiol Rev 2004; 17: $903-925$, table of contents

30 Chaudhuri A, Martinez-Martin P, Kennedy PG et al. EFNS guideline on the management of communityacquired bacterial meningitis: report of an EFNS Task Force on acute bacterial meningitis in older children and adults. Eur J Neurol 2008; 15: 649-659

31 Greisen K, Loeffelholz M, Purohit A et al. PCR primers and probes for the 16S rRNA gene of most species of pathogenic bacteria, including bacteria found in cerebrospinal fluid. J Clin Microbiol 1994; 32: 335-351

32 Srinivasan L, Pisapia JM, Shah SS et al. Can broadrange $16 \mathrm{~S}$ ribosomal ribonucleic acid gene polymerase chain reactions improve the diagnosis of bacterial meningitis? A systematic review and meta-analysis. Ann Emerg Med 2012; 60: 609-620 e602

33 Steiner I, Schmutzhard E, Sellner J et al. EFNS-ENS guidelines for the use of PCR technology for the diagnosis of infections of the nervous system. Eur J Neurol 2012; 19: 1278-1291

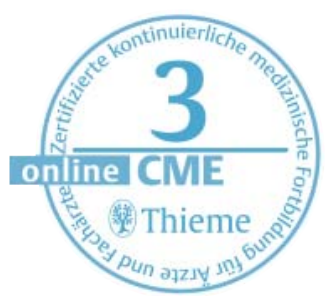


34 Reiber H, Lange P. Quantification of virus-specific antibodies in cerebrospinal fluid and serum: sensitive and specific detection of antibody synthesis in brain. Clin Chem 1991; 37: 1153-1160

35 Diener H, Weimar C. Leitlinien für Diagnostik und Therapie in der Neurologie. 5. ed. Stuttgart: Thieme; 2012

36 Zettl UK, Lehmitz R, Mix E. Klinische Liquordiagnostik. 2. ed. Berlin: de Gruyter; 2005

37 Sussmuth SD, Brettschneider J, Spreer A et al. Current cerebrospinal fluid diagnostics for pathogen-related diseases. Nervenarzt 2013; 84: 229-244

38 Proulx N, Frechette D, Toye B et al. Delays in the administration of antibiotics are associated with mortality from adult acute bacterial meningitis. QJM 2005; 98: 291-298

39 Bonadio WA. The cerebrospinal fluid: physiologic aspects and alterations associated with bacterial meningitis. Pediatr Infect Dis J 1992; 11: 423-431

40 McGrath N, Anderson NE, Croxson MC et al. Herpes simplex encephalitis treated with acyclovir: diagnosis and long term outcome. J Neurol Neurosurg Psychiatry 1997; 63: $321-326$

41 Raschilas F, Wolff M, Delatour F et al. Outcome of and prognostic factors for herpes simplex encephalitis in adult patients: results of a multicenter study. Clinical infectious diseases: an official publication of the Infectious Diseases Society of America 2002; 35: $254-260$

42 Tyler KL. Herpes simplex virus infections of the central nervous system: encephalitis and meningitis, including Mollaret's. Herpes 2004; 11 (Suppl 2): 57A$64 \mathrm{~A}$

43 Aurelius E, Johansson B, Skoldenberg B et al. Rapid diagnosis of herpes simplex encephalitis by nested polymerase chain reaction assay of cerebrospinal fluid. Lancet 1991; 337: 189-192

44 Revello MG, Baldanti F, Sarasini A et al. Quantitation of herpes simplex virus DNA in cerebrospinal fluid of patients with herpes simplex encephalitis by the polymerase chain reaction. Clinical and diagnostic virology 1997; 7: 183-191
45 Weil AA, Glaser CA, Amad Z et al. Patients with suspected herpes simplex encephalitis: rethinking an initial negative polymerase chain reaction result. Clinical infectious diseases: an official publication of the Infectious Diseases Society of America 2002; 34: $1154-1157$

46 Rauer S, Kaiser R, Kölmel HW et al. Neuroborreliose. In: Diener $\mathrm{H}$, Weimar $\mathrm{C}$ eds Leitlinien für Diagnostik und Therapie in der Neurologie. 5. ed. Thieme: 2012: 513-522

47 Mygland A, Ljostad U, Fingerle $V$ et al. EFNS guidelines on the diagnosis and management of European Lyme neuroborreliosis. Eur J Neurol 2010; 17: 8 -16, e11 e14

48 Spreer A, Djukic M, Nau R et al. Update Neuroborreliose - Neues und Bewährtes. Aktuelle Neurologie 2013; 40: 7-15

49 Djukic M, Schmidt-Samoa C, Lange P et al. Cerebrospinal fluid findings in adults with acute Lyme neuroborreliosis. J Neurol 2011; 259: 630-636

50 Schmidt C, Plate A, Angele B et al. A prospective study on the role of CXCL13 in Lyme neuroborreliosis. Neurology 2011; 76: $1051-1058$

51 Kaiser R, Holzmann H. Laboratory findings in tickborne encephalitis - correlation with clinical outcome. Infection 2000; 28: 78-84

52 Kaiser R, Archelos-Garcia J, Jilg W et al. FrühsommerMeningoenzephalitis (FSME). In: Diener H, Weimar C eds Leitlinien für Diagnostik und Therapie in der Neurologie. 5. ed. Stuttgart: Thieme; 2012: 554-559

53 Reiber H, Peter JB. Cerebrospinal fluid analysis: disease-related data patterns and evaluation programs. J Neurol Sci 2001; 184: 101 - 122

54 Nau R, Behnke-Mursch J, Eiffert $H$ et al. Hirnabszess. In: Diener $\mathrm{H}$, Weimar $\mathrm{C}$ eds, Leitlinien für Diagnostik und Therapie in der Neurologie. 5. ed. Stuttgart: Thieme; 2012: 505-512

55 Bitsch A, Nau R, Hilgers $R$ et al. Focal neurologic deficits in infective endocarditis and other septic diseases. Acta Neurol Scnad 1996; 94: 279-286

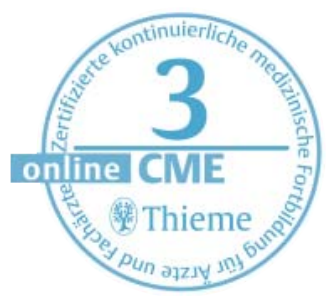




\section{CME-Fragen Liquordiagnostik bei erregerbedingten neurologischen Erkrankungen}

1 In welchem Fall besteht vor Durchführung einer diagnostischen Liquorpunktion eine dringende Indikation für eine cerebrale Bildgebung?

A Schmerzhafte Nackensteife

B Isolierte periphere Fazialisparese

C Fokalneurologisch unauffälliger Patient mit Fieber und Kopfschmerz

D Vorhandensein von Stauungspapillen

E Studienteilnehmer

2 Welche der folgenden Aussagen zu der Durchführung einer diagnostischen Liquorpunktion ist falsch?

A Die Wahrung steriler Punktionsbedingungen umfasst die gründliche Hautdesinfektion, die Verwendung eines sterilen Abdeck- oder Lochtuchs, das Tragen steriler Handschuhe und oft das Tragen eines Mundschutzes.

B Oberflächliche oder tiefe Entzündungen im Punktionsbereich stellen eine Kontraindikation dar.

C Eine Punktion kranial von LWK 3/4 (bereits ab LWK 2/3) geht mit einem erhöhten Risiko einer Konus-/Kauda-Schädigung einher.

D Die Verwendung einer 22G-Sprotte-Nadel vermindert das Risiko eines postpunktionellen Syndroms im Vergleich zu einer 22G-Quincke-Nadel von 18,9\% auf 6,7\%.

E Die Einnahme von NOAK („,neue orale Antikoagulanzien“) braucht für die Durchführung einer diagnostischen Liquorpunktion nicht pausiert zu werden.

3 Für eine optimale Analytik bedarf es stets der Einsendung von Liquor cerebrospinalis gemeinsam mit zeitgleich entnommenem EDTA-Blut zeitnah entnommenem Serum ( $<2$ Stunden)

C sequenziell im Abstand von 2 Stunden entnommenen Liquorproben

D Blutkulturen

E Rachenabstrich

Welche Normalwerte der Liquordiagnostik treffen für einen 30-jährigen Menschen zu?

Zellzahl $<12 / \mu l$, Laktat $<2,1 \mathrm{mmol} / \mathrm{l}$, Gesamteiweiß $<800 \mathrm{mg} / \mathrm{l}, \mathrm{QAlb} \leq 7,5 \times 10^{-3}$

B Zellzahl $>5 / \mu l$, Laktat $>2,1 \mathrm{mmol} / \mathrm{l}$, Gesamteiweiß $<1000 \mathrm{mg} / \mathrm{l}, \mathrm{QAlb} \leq 4,5 \times 10^{-3}$

C Zellzahl $<3 / \mu \mathrm{l}$, Laktat $>3,5 \mathrm{mmol} / \mathrm{l}$, Gesamteiweiß $<500 \mathrm{mg} / \mathrm{l}, \mathrm{QAlb} \leq 4,5 \times 10^{-3}$

D Zellzahl $<5 / \mu \mathrm{l}$, Laktat $<2,1 \mathrm{mmol} / \mathrm{l}$, Gesamteiweiß $<500 \mathrm{mg} / \mathrm{l}, \mathrm{QAlb} \leq 6 \times 10^{-3}$

E Zellzahl $<5 / \mu l$, Laktat $<3,0 \mathrm{mmol} / \mathrm{l}$, Gesamteiweiß $<800 \mathrm{mg} / \mathrm{l}, \mathrm{QAlb} \leq 9 \times 10^{-3}$
5

Wie ist die empfohlene Präanalytik bei V. a. eine bakterielle Meningitis?

A Lagerung bei $4{ }^{\circ} \mathrm{C}$ für maximal 48 Stunden vor Verarbeitung

B Lagerung und Transport bei $-20^{\circ} \mathrm{C}$

C Transport des unzentrifugierten Liquors bei Raumtemperatur in $<30$ Minuten

D Lagerung und Transport im Brutschrank vor Anlage der Kultur

E Versand der Überstandes nach Zentrifugation über Postweg

Welches ist die vorrangige diagnostische Methode zum Erregernachweis bei $V$. a. Herpesenzephalitis? Erregerkultur aus Liquor cerebrospinalis Mikroskopie von Zytospinpräparat oder Liquorausstrich Spezifischer Antikörperindex Hirnbiopsie Polymerase-Kettenreaktion aus Liquor cerebrospinalis

7 Welcher Befund weist keine intrathekale Immunglobulinsynthese nach?

A Vorhandensein isolierter oligoklonaler Banden im Liquor

B Lage des Punktes $\mathrm{Q}_{\mathrm{Ig}}$ gegen $\mathrm{Q}_{\mathrm{Alb}}$ aufgetragen im Bereich 4 des Reiber-Quotientendiagramms

C Borrelien-Antikörper-Index von 3,5

D Identische Banden eines Paraproteins in Liquor und Serum in der IEF (Muster 5)

E Positive MRZ-Reaktion bei chronisch-entzündlicher ZNSErkrankung (erhöhte AI-Werte gegen Masern, Röteln, Zoster)

8 Bei welcher Erkrankung spielt die Liquor-PCR in der Erregerdiagnostik keine Rolle? Frühsommer-Meningoenzephalitis

Ambulant erworbene eitrige Meningitis

Herpes-simplex-Enzephalitis

Neurotuberkulose

Progressive multifokale Leukenzephalopathie 
9

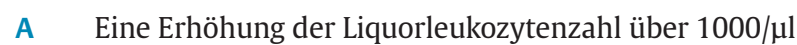

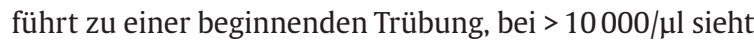
der Liquor eitrig aus.

B „Spinngewebsgerinnsel“ zeigen eine massive Eiweißerhöhung an.

C Quantifizierung von Liquorzellen und der direkte Erregernachweis sind voll automatisierbar, so dass auf die mikroskopische Beurteilung verzichtet werden kann.

D Eine Meningeosis carcinomatosa kann aufgrund hoher Eiweiß- und Laktatwerte differentialdiagnostisch an eine Neurotuberkulose denken lassen.

E Um eine folgenschwere Fehldiagnose einer apurulenten bakteriellen Meningitis zu vermeiden, müssen neben der Beurteilung der Zellzahl auch stets Laktat, Gesamteiweiß und das klinische Bild des Patienten beachtet werden.

\section{0}

Welche Aussage zu einem Hirnabszess ist falsch?

A Bei einem Hirnabszess liegt oft eine Mischinfektion aus aeroben und anaeroben Bakterien vor.

B Die entscheidende diagnostische Maßnahme ist die cerebrale Bildgebung mittels MRT oder alternativ CT mit Kontrastmittel.

C Bei raumfordernden Hirnabszessen ist eine Liquorentnahme wegen der Gefahr der Herniation kontraindiziert.

D Die Lumbalpunktion ist von entscheidender Bedeutung zur Erregersicherung.

E Der Liquor zeigt eine unspezifische leichte bis mäßige Pleozytose und Proteinerhöhung, selten kann er auch normal sein. 